\title{
Predicting frequency distribution and influence of sociodemographic and behavioral risk factors of Schistosoma mansoni infection and analysis of co-infection with intestinal parasites
}

\author{
Carla V.V. Rollemberg, ${ }^{1}$ Marília M.B.L. Silva, ${ }^{2}$ Karla C. Rollemberg, ${ }^{1}$ Fábio R. Amorim, ${ }^{1}$ \\ Nayanna M.N. Lessa, ${ }^{1}$ Marcos D.S. Santos, ${ }^{1}$ Acácia M.B. Souza, ${ }^{2}$ Enaldo V. Melo, ${ }^{1}$ \\ Roque P. Almeida, ${ }^{3}$ Ângela M. Silva, ${ }^{1}$ Guilherme L. Werneck, ${ }^{4,5}$ Mario A. Santos, ${ }^{1}$ \\ José A.P. Almeida, ${ }^{3}$ Amélia R. Jesus ${ }^{1,4}$ \\ 'Laboratory of Molecular Biology, University Hospital, Federal University of Sergipe; \\ 2Post-doc Geography Unit, Department of Geography, Federal University of Sergipe; \\ ${ }^{3}$ Department of Geology, Federal University of Sergipe; ${ }^{4}$ Research Institute in \\ Immunology, National Institute of Science and Technology, Brazilian Research \\ and Technology Council, São Paulo; ${ }^{5}$ Department of Social Medicine, Institute \\ of Medicine and Health, Public University of Rio de Janeiro-Fundação Oswaldo Cruz, \\ Rio de Janeiro, Brazil
}

\begin{abstract}
Correspondence: Amélia Ribeiro de Jesus, Laboratory of Molecular Biology, University Hospital, Federal University of Sergipe, rua Claudio Batista s/n, Sanatório, Aracaju, Sergipe, Brazil. Tel: +55.79 .21051806 .

E-mail: jesus-amelia@uol.com.br
\end{abstract}

Key words: Schistosomiasis; Schistosoma mansoni; Soil-transmitted helminths; Intestinal parasites; Risk factors.

Ethical approval: approved by the Institutional review board from the University Hospital of the Universidade Federal de Sergipe, Brazil. All individuals and guardians of minors of 18 years have signed an informed consent (CEP UFS, SISNEP CAAE-0022.0.107.000-08).

Acknowledgements: we thank the people of Ilha das Flores, Sergipe, Brazil who accepted to participate in this study. We also thank the Health Care agents Jorge Feitosa and Edmilson Nicolaus dos Santos, and the medical students Cybele Santos, Debora Barreto, Cinthia Andrade and Karina Pessoa for participating together with the research team in the clinical, epidemiological and parasitological survey.

Funding: edital MS/CNPq/FAPITEC/SE/SES $N^{\circ}$ 06/2007 - PPSUS, $\mathrm{n}^{\circ} 19.203$ 00775/2007-3. CAPES Edital 032/2010. ARJ and RPA are scientists from the Brazilian Research and Technology Council (CNPq).

Conflict of interest: the authors declare no potential conflict of interest.

Received for publication: 7 January 2015.

Revision received: 10 March 2015.

Accepted for publication: 12 March 2015.

(O) Copyright C.V.V. Rollemberg et al., 2015

Licensee PAGEPress, Italy

Geospatial Health 2015; 10:303

doi:10.4081/gh.2015.303

This article is distributed under the terms of the Creative Commons Attribution Noncommercial License (by-nc 3.0) which permits any noncommercial use, distribution, and reproduction in any medium, provided the original author(s) and source are credited.

\begin{abstract}
Geospatial analysis was used to study the epidemiology of Schistosoma mansoni, intestinal parasites and co-infections in an area (Ilha das Flores) in Sergipe, Brazil. We collected individually georeferenced sociodemographic, behavioral and parasitological data from 500 subjects, analyzed them by conventional statistics, and produced risk maps by Kernel estimation. The prevalence rates found were: $S$. mansoni (24.0\%), Trichuris trichiura (54.8\%), Ascaris lumbricoides (49.2\%), Hookworm (17.6\%) and Entamoeba histolytica (7.0\%). Only $59 / 500(11.8 \%)$ individuals did not present any of these infections, whereas $279 / 500(55.8 \%)$ were simultaneously infected by three or more parasites. We observed associations between $S$. mansoni infection and various variables such as male gender, being rice farmer or fisherman, low educational level, low income, water contact and drinking untreated water. The Kernel estimator indicated that high-risk areas coincide with the poorest regions of the villages as well as with the part of the villages without an adequate sewage system. We also noted associations between both $A$. lumbricoides and hookworm infections with low education and low income. A. lumbricoides infection and T. trichiura infection were both associated with drinking untreated water and residential open-air sewage. These findings call for an integrated approach to effectively control multiple parasitic infections.
\end{abstract}

\section{Introduction}

Schistosomiasis and intestinal parasites are common in Asia, Africa and Latin America (Chitsulo et al., 2000; Hotez et al., 2010). In 2013, the World Health Organization estimated that there are 249 million people requiring treatment for schistosomiasis, while the actual number of people treated in 2012 was only 42.1 million (WHO, 2014). More than 1.3 billion people worldwide are infected by Ascaris lumbricoides, 1.25 billion by Trichuris trichiura (WHO, 2010) and 740 million by hookworm caused by the nematodes Necator americanus and 
Ancylostoma duodenale (Da Silva et al., 2003). Protozoal infections are also common problems in the developing countries with Giardia lamblia affecting nearly $33 \%$ of general populations, while Entamoeba histolytica prevalence often reaches $50 \%$ and is estimated to cause more than 100,000 deaths per year (WHO, 2010).

Polyparasitism represents a major health problem and affects a substantial proportion of the populations in the tropics (Hotez et al., 2010). However, few studies address prevalence rates, the types of interaction that occur between different species of parasites, their spatial distributions, sociodemography and the behavioral factors associated with these infections. The ability to predict the distribution of co-infections at large geographical scales has important implications for the design of control programs for neglected tropical diseases in general (Brooker et al., 2002; Brooker and Clements, 2009; Hotez et al., 2010).

Due to the diversity of sociodemographic and development status among regions there is a need for large-scale parasitological surveys in Brazil. Such studies were conducted in the 1970 s, while more recent studies have tended to be local and are, therefore, not capable of reflecting the situation in the country as a whole. However, a multicenter study of 7-to-14-year-old students in 10 Brazilian states recorded 55.3\% intestinal parasites, such as A. lumbricoides, T. trichiura and in particular G. lamblia (Campos et al., 2002). Spatial modelling of coinfections has largely been ignored in Brazil, but some studies have investigated the spatial distribution of co-infection between Schistosoma mansoni and hookworm (Bethony et al., 2001; Gazzinelli et al., 2001; Raso et al., 2006, 2007).

We describe the prevalence of $S$. mansoni alone as well as co-infection with intestinal parasites, such as soil transmitted helminths (STHs) and protozoa in the municipality of Ilha das Flores, Sergipe, Brazil, known to have high rates of prevalence for these parasites (Rollemberg et al., 2011). Using this rural community as a model, our objective was also to investigate the association of these infections with known sociodemographic and behavioral risk factors. The importance of this study was to point out and localize the main risk factors to be the target for interventions that could benefit affected populations. We used geographic information systems (GIS) with improved techniques for storage, query and analytical software designed to identify variables that do not only reveal disease distribution, but also the sociodemographic and behavioral factors influencing the disease distribution. Geo-localization was used to prove the influence of the surface water contamination by primitive sewage system in the higher transmission areas of Ilha das Flores. Although this study was primarily aimed at evaluating the local situation in this community, we feel that our approach can also used as a tentative model for other parts of North-Eastern Brazil.

\section{Materials and Methods}

The present epidemiological study, combining a field study with geolocalization using GIS, was performed to improve our understanding of the sociodemographic, behavioral factors involved including the influence of surface water contamination on acquisition of $S$. mansoni and other parasitic infections.

\section{Study area}

The study took place in Ilha das Flores municipality located $135 \mathrm{~km}$ from Aracaju, the capital of Sergipe State, Brazil (Figure 1). This municipality is one of the major producers of rice in the Northeast and is situated on the banks of the São Francisco River, the main river irri- gating North-Eastern Brazil. It has the geographic coordinates of $10^{\circ} 26^{\prime} 05^{\prime \prime}$ South and $36^{\circ} 32$ '21"West.

Ilha das Flores comprises four areas, i.e. the city center and the villages of Bongue, Serrão and Bolivar. In 2007, it had 8568 inhabitants, $85.4 \%$ of whom with access to potable water, but only intermittently. Thus, no one in the area has constant access to tap water, so people must use surface water for their daily activities. According to the Brazilian Institute of Geography and Statistics (IBGE) data from 2007, only $3.3 \%$ of the population has sanitation coverage (IBGE, 2007). There is an extensive but primitive irrigation system that was created for rice plantation and other purposes, taking its water from the local river through two pump stations, one located in the city center and the other in the village of Serrão. Water is returned through a stream leading back into the river. Local people use the irrigation canals for many different household activities and these canals also receive waste from open sewers. Additionally, the canals are infested by snails of the Biomphalaria species, the intermediate host of $S$. mansoni (Barboza et al., 2012). The combination of contamination of surface waters with open-air sewage and the presence of Biomphalaria species are important determinants for the transmission of schistosomiasis.

\section{Study design}

This was a cross-sectional, epidemiological study in the rural areas of Ilha das Flores between September 2008 and May 2010. The infections tested for included $S$. mansoni and the STHs A. lumbricoides, hookworm and T. trichiura. The protozoal infections investigated were E. histolytica, the non-pathogenic E. coli, G. Lamblia, Enterobius vermicularis and Strongyloides stercoralis. To understand the consequences of these infections for the individuals' health, symptoms related to these parasite infections were also evaluated.

\section{The georeferenced database}

Aerial photography from 2003 at the 1:25,000 scale was obtained from the State Planning Department (SEPLAN) in Sergipe. These aerial photographs were georeferenced through the acquisition of control points acquired with a Global Positioning System (GPS) instrument (Trimble) with a $2.5 \mathrm{~m}$ resolution after correction. A georeference database was created using Spring, v 5.2 (National Institute for Space

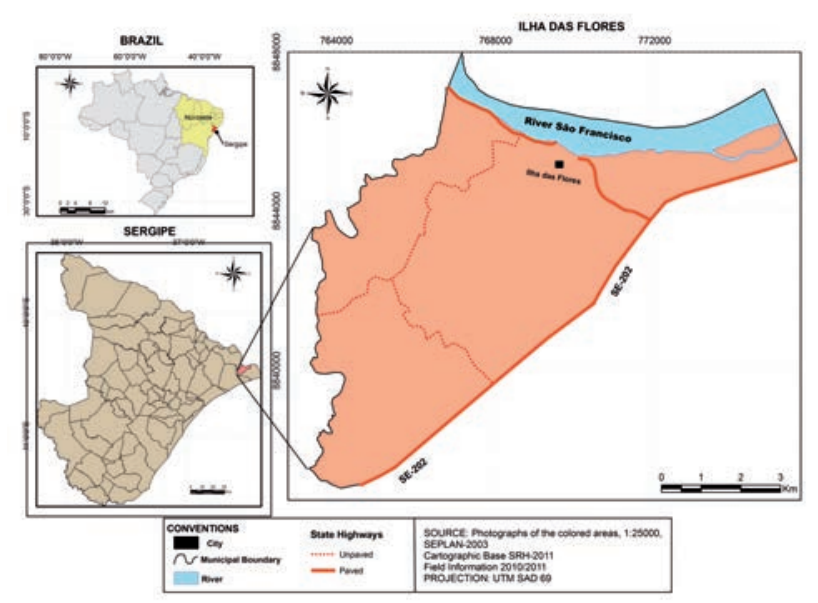

Figure 1. The study area and its localization in the state of Sergipe, Brazil. 
Research). The urban network information plan was superimposed on the aerial photograph of the municipality by means of the vector editing section of the Spring software, while the households were mapped with GPS during home visits by the field team. Sociodemographic and behavioral data collected in epidemiological survey (described below) were entered into the ACCESS program database and exported to the georeferenced Spring database.

\section{Data collection}

According to data of the schistosomiasis control program (PCE) from 2007, Ilha das Flores had a $46.5 \%$ prevalence of $S$. mansoni infection (Rollemberg et al., 2011). However, we observed that the health agents collected the parasitological data for the PCE from subjects living in areas of particular risk for infection, which could overestimate the prevalence, so we decided to use a prevalence of $30 \%$ to calculate our sample size, which was done by binomial analysis using Stata 7.0 (Stata, College Station, TX, USA), with a 95\% confidence interval (CI) of 26.0 to 34.2. Based on that, our calculated sample size amounted to 500 individuals, or 100 families (considering an average of 5 persons per family).

Parasitological data regarding $S$. mansoni and intestinal parasites were obtained from 100 randomly selected families in order to exceed the calculated sample size. The total number of study subjects included 570 individuals proportionally distributed between the four localities that compose the municipality of Ilha das Flores. Stool samples were collected from each member of the household and microscopic examination was performed using two methods: i) two slides from a single stool sample were quantitatively examined according to Kato-Katz et al. (1972); and ii) in order to increase the sensitivity and to see protozoa, the three-fecal-test qualitative method (Gomes et al., 2004) was used. This test is based on microscopic examination of three pooled fecal samples collected on three different days and preserved in formalin. The overall result was considered positive if at least one egg or cyst (protozoa) was detected by any of the methods.

The field team distributed a questionnaire with 87 questions to every resident. The variables analysed in the present study were a subsection consisting of age, gender, area of residence, place of birth and time of residence in the same (endemic) area, housing conditions and sanitation, i.e. water supply unadjusted, electricity, general sewage network and type of sewage system (open-air sewage or septic tank); degree of schooling (illiterate, elementary school, high school, or undergraduate); labour activities (current employment and/or other work activities); family income [translated into US dollars (USD) in this manuscript]; and behavioral risk factors for acquiring the diseases under study, such as exposure to surface water and/or soil (history, time, and location of water contact; hygiene habits, such as washing of hands and vegetables in relation to meals, and use of shoes). Clinical symptoms in the last year, such as diarrhea, blood and mucus in stool, were also evaluated. All members of the community testing positively in the parasitological examination were treated with praziquantel $(50 \mathrm{mg} / \mathrm{kg}$ of body weight) for schistosomiasis, albendazole (400 mg single dose for children above 2 years old and adults) for the STHs and metronidazole for the intestinal protozoa, according to the type of parasite found $(E$. histolytica, 500 to $700 \mathrm{mg}$ three times a day for 5 to 10 days) and for giardiasis ( $2 \mathrm{~g}$ once a day for 3 days).

\section{Statistical analysis}

All variables collected (questionnaire outcomes and the results of the parasitological examinations) were entered into SPSS Statistics, version 17 (IBM Corp., Armonk, NY, USA) and MlwiN, version 2.28 soft- ware (Rasbash et al., 2012) by two investigators. Descriptive data analysis was performed for calculation of the prevalence of all the parasitic infections and co-infections under study. The sociodemographic, and behavioral variables, in absolute and percentage frequencies, were organized in charts. We evaluated the associations between infections by the different parasites under study with the above mentioned sociodemographic and behavioral risk variables, calculating prevalence ratios including $95 \% \mathrm{CI}$ using logistic regression for $S$. mansoni and chi-square or the Fisher exact test for the other parasite species. Periodically referred clinical symptoms in the last year, such as diarrhea, blood and mucus in stools were investigated for potential association with infection by $S$. mansoni and intestinal parasites by calculating prevalence ratios including the $95 \% \mathrm{CI}$ using chi-square or the Fisher exact test. The accepted level of statistical significance was $\mathrm{P}<0.05$ for all tests carried out.

\section{Spatial analysis}

Mapping of the spatial distribution of schistosomiasis in the municipality was performed to evaluate the geographical variation in its occurrence to identify the distribution of risk and model its occurrence. The software Crime Stat III (http://www.icpsr.umich.edu/CrimeStat/) was used to develop a shapefile of a dual kernel, or kernel ratio for the four study locations (city center, Serrao, Bolivar, and Bongue). This was calculated from the ratio of number of positive individuals for schistosomiasis per household, by number of individuals in the household. The risk was expressed as the probability of occurrence with values ranging from 0 to 1 . A circle with a radius of $4 \mathrm{~m}$ (the minimum distance between households) centred on positive individuals, was taken as the region of potential influence where nearby events could have contributed to the results. The thematic map from the results of Kernel density estimator was created in ArcView GIS version 3.1 (ESRI, Redlands, CA, USA), which is compatible to Crime Stat III. The Kernel density layer was superimposed on the thematic maps of urban areas that showed the location of the residences, from which the questionnaires and parasitological data had been collected by the field team. We also created cartographic maps of the distribution of the rice fields, urban area and surface water in ArcView GIS version 3.1, to analyze the proximity of the houses of the risk areas for $S$. mansoni infection.

\section{Results}

Out of the originally selected 570 individuals, 500 individuals completed the survey and participated in accompanying stool examinations, while seventy persons were excluded because they did not perform the parasitological tests. We found 120 individuals with positive stool examination for $S$. mansoni (24\%). Among those infected, $34.8 \%$ were female with an age range from 9 to 73 (mean $\pm \mathrm{SD}=30.7 \pm 14.44$ and median of 30 ); and $65.2 \%$ were male with an age range from 2 to $72($ mean $\pm \mathrm{SD}=23.6 \pm 13.68$ and median of 19$)$. Multiple parasitism was common in subjects from 11 to 20 years old.

Frequency statistics revealed that only 59 (11.8\%) of all individuals did not present any co-infection, whereas 279/500 (55.8\%) had three or more parasites simultaneously. Among the 120 schistosomiasis patients, only 13/120 (10.8\%) were exclusively infected with $S$. mansoni. Table 1 shows the frequencies of $S$. mansoni infection and coinfections with other intestinal parasites.

We detected a positive association between $S$. mansoni and male gender, low-level education and low income. We also observed positive associations between $S$. mansoni infection and water contact (both in 
the form of drinking untreated water and direct contact with surface water). With respect to profession, we found a strong association for rice farmer or fisherman. There were also associations between schistosomiasis and simultaneous trichuriasis and STH infection. Table 2 shows the association of STHs and protozoal infections with sociodemographic and behavioral risk factors. The STHs detected were $T$. trichiura, A. lumbricoides, hookworm, E. vermicularis and $S$. stercoralis. The protozoal infections detected were $E$. histolytica, $G$. lamblia, and the non-pathogenic $E$. coli. We found an association between open-air sewerage with T. trichiura and STH infection, association of drinking untreated water with infection by A. lumbricoides and T. trichiura as well as with STH in general, and monthly family incomes <USD 300 (the minimum salary defined by the Brazilian Government) associated with A. lumbricoides and hookworm infection and with STH in general. Diarrhea and blood in stool were both associated with $S$. mansoni infection, while diarrhea alone was commonly seen together with infection due to A. lumbricoides and T. trichiura (Table 3).

The spatial analysis is presented as descriptive maps showing raw prevalence estimates of $S$. mansoni infection with the kernel estimator. The highest risk areas were in the southern part of Serrão village, in the south-eastern part of Bolivar village, in the poorest area of the city center and along the river bank in Bongue village. The majority of the individuals $(393 / 500,78.6 \%)$ in these villages live in houses with septic tanks installed, while others $(25 / 500,5 \%)$ belong to a general sewage network or have open-air sewage $(55 / 500,11 \%)$. A minority of the individuals (27/500. 5.4\%) did not answer to this question. We observed that the majority of the septic tanks were not adequately built and therefore contaminated the surrounding soil. We also observed that there was a higher number of open-air sewage/septic tanks than homes connected to a sewage network in the areas with higher risk for $S$. mansoni (Figure 2). We also observed in the cartographic maps a proximity of the rice field, surface water and the urban area (Figure 3 ).

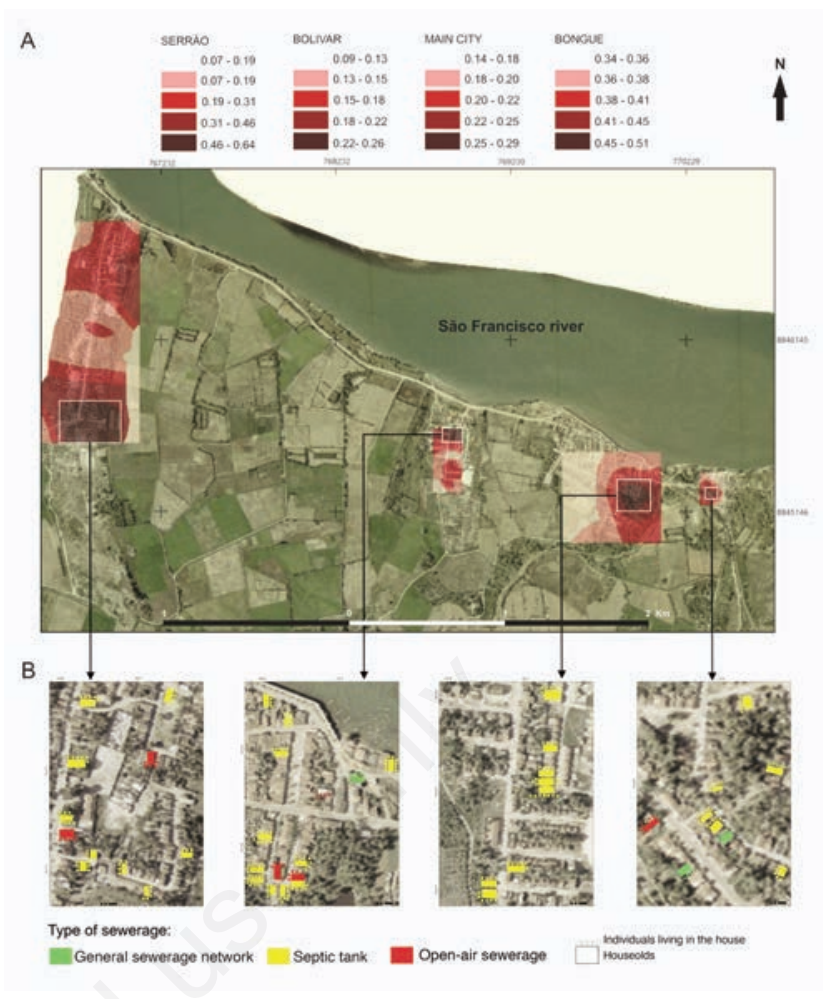

Figure 2. (A) Risk areas for S. mansoni infection in the urban villages of Ilha das Flores, expressed as a probability of occurrence with values ranging from 0 to 1 . (B) Each of the squares below shows a detail of the hot spot areas of the villages of Serrão, Bolivar, Main City, and Bongue, respectively. Types of sewage system from the houses marked in the map: houses with general sewage network are painted in green; with septic tank in yellow and open air sewage in red. The round dots around the houses are the individuals living in the houses.

Table 1. Prevalence of schistosomiasis and intestinal parasitic infections in Ilha das Flores.

\begin{tabular}{|c|c|c|c|}
\hline & Parasitic infections & $\begin{array}{l}\text { No. of infections } \\
\text { (Total tested=500) }\end{array}$ & Prevalence (\%) \\
\hline \multicolumn{4}{|l|}{ Parasite } \\
\hline & Schistosoma mansoni & 120 & 24.0 \\
\hline & Ascaris lumbricoides & 246 & 49.2 \\
\hline & Entamoeba histolyticaldispar & 35 & 7.0 \\
\hline & Entamoeba coli & 128 & 25.6 \\
\hline & Enterobius vermicularis & 18 & 3.6 \\
\hline & Giardia lamblia & 25 & 5.0 \\
\hline & Hookworm & 88 & 17.6 \\
\hline & Strongyloides stercoralis & 4 & 0.8 \\
\hline & Tricuris trichiura & 274 & 54.8 \\
\hline \multicolumn{4}{|l|}{ Co-infection with $S$. mansoni and intestinal parasites } \\
\hline & S. mansoni + A. lumbricoides & 61 & 50.8 \\
\hline & S. mansoni+T. trichiura & 79 & 65.8 \\
\hline & S. mansoni $+\mathrm{STH}^{\circ}$ & 62 & 51.7 \\
\hline & S. mansoni+protozoa ${ }^{\#}$ & 10 & 8.3 \\
\hline & S. mansoni + STH $^{\circ}+$ protozoa $^{\#}$ & 35 & 29.2 \\
\hline & S. mansoni without co-infection & 13 & 10.8 \\
\hline
\end{tabular}

\footnotetext{
${ }^{\circ}$ All soil-transmitted helminths; \#G. lamblia and $E$. histolytica.
} 


\section{Discussion}

Schistosomiasis is a focal disease and it is important to study endemic regions to build a model to understand the dynamics of the sociodemographic and behavioral determinants of its transmission. However, this disease should not be investigated in isolation since, in most endemic areas, schistosomiasis is not the only chronic parasitic infection found. It is estimated that $26-68 \%$ of individuals with schistosomiasis are carriers of other helminth infections such as hookworm, A. lumbricoides or T. trichiura (Bundy et al., 1991). Most of the endemic areas are prevalent $(\geq 10 \%)$ or hyperendemic (prevalence $\geq 50 \%$ ) for STH infections. Due to the requirement of an aquatic snail intermediate host for transmission, areas endemic for schistosomiasis are commonly near perennial water reservoirs that, if contaminated with fecal matter, sustain the $S$. mansoni life-cycle. The contaminated water source also contaminates the soil and fresh food with a variety of helminth and protozoal parasites (Clements et al., 2010).

In the present study, we studied a known endemic area where $89.2 \%$

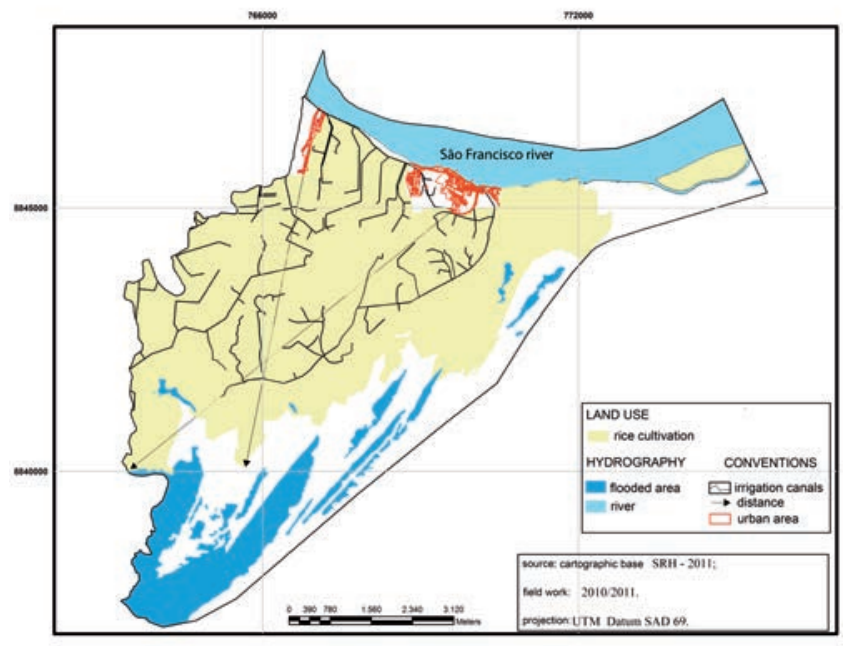

Figure 3. Land use and irrigation system in the study area.

Table 2. Associations of $S$. mansoni and other intestinal parasite infections with sociodemographic and behavioral factors and concomitant infections in Ilha das Flores.

\begin{tabular}{|c|c|c|c|c|}
\hline Parasites/socio-economic factors & & PR & $95 \% \mathrm{CI}$ & $\mathbf{P}$ \\
\hline S. mansoni & $\begin{array}{l}\text { Age } \\
\text { Male gender } \\
\text { Education<elementary school } \\
\text { Monthly income<USD } 300.00 \\
\text { Drinking untreated water } \\
\text { Being a rice farmer } \\
\text { Being a fisherman } \\
\text { Contact with surface water sources } \\
\text { Simultaneous T. trichiuris infection } \\
\text { Simultaneous intestinal parasites }\end{array}$ & $\begin{array}{l}2.2 \\
2.0 \\
7.1 \\
1.8 \\
6.9 \\
2.7 \\
3.3 \\
1.9 \\
1.8^{\circ} \\
1.7^{\circ}\end{array}$ & $\begin{array}{c}1.39-3.64 \\
1.27-3.26 \\
2.41-20.93 \\
1.28-2.60 \\
2.44-19.86 \\
1.29-5.40 \\
1.39-7.69 \\
1.36-2.59 \\
1.19-2.80 \\
1.00-2.70\end{array}$ & $\begin{array}{l}0.008 \\
0.003 \\
<0.001 \\
0.0005 \\
<0.001 \\
<0.001 \\
<0.001 \\
<0.001 \\
0.006 \\
0.056\end{array}$ \\
\hline A. lumbricoides & $\begin{array}{l}\text { Monthly income <USD } 300.00 \\
\text { Drinking untreated water }\end{array}$ & $\begin{array}{l}2.0 \# \\
1.6 \#\end{array}$ & $\begin{array}{l}1.4-2.9 \\
1.1 .-2.3\end{array}$ & $\begin{array}{l}0.02 \\
0.02\end{array}$ \\
\hline T. trichiura & $\begin{array}{l}\text { Commonly walk barefoot } \\
\text { Drinking untreated water } \\
\text { Open-air sewage at home }\end{array}$ & $\begin{array}{l}1.6 \# \\
1.7 \# \\
1.6 \#\end{array}$ & $\begin{array}{l}1.1-2.4 \\
1.1-2.4 \\
1.1-2.4\end{array}$ & $\begin{array}{l}0.02 \\
0.02 \\
0.03\end{array}$ \\
\hline Hookworm & $\begin{array}{l}\text { Monthly income <USD } 300.00 \\
\text { Drinking untreated water }\end{array}$ & $\begin{array}{l}1.8 \# \\
1.5 \#\end{array}$ & $\begin{array}{l}1.1-3.0 \\
0.9-2.5\end{array}$ & $\begin{array}{l}0.02 \\
0.01\end{array}$ \\
\hline $\mathrm{STH}^{\circ}$ & $\begin{array}{l}\text { Monthly income <USD } 300.00 \\
\text { Drinking untreated water } \\
\text { Open sewage at home }\end{array}$ & $\begin{array}{l}1.9^{\circ} \\
2.6^{\circ} \\
2.9^{\circ}\end{array}$ & $\begin{array}{l}1.3-2.9 \\
1.5-4.3 \\
1.9-4.6\end{array}$ & $\begin{array}{l}0.03 \\
0.03 \\
0.04\end{array}$ \\
\hline
\end{tabular}

PR, prevalence ratio (odds ratio interpreted as a PR); CI, onfidence interval; USD, US dollars; STH, soil-transmitted helminths. ${ }^{\circ}$ Fisher exact test; \#logistic regression.

Table 3. Associations of intestinal parasitic infections and $S$. mansoni with clinical symptoms.

\begin{tabular}{llccc}
\hline Parasites & PR & Diarrhea & \multicolumn{2}{c}{ Blood in stool } \\
S. mansoni & $1.7^{\circ}$ & $95 \% \mathrm{CI}$ CI & $1.0-29$ \\
A. lumbricoides & $1.7^{\circ}$ & $1.1-2.6$ & $1.7^{\circ}$ & $0.9-2.3$ \\
\hline T. trichiura & $1.5^{\circ}$ & $1.2-2.6$ & $1.5^{\circ}$ & $0.8-2.2$ \\
Hookworm & $1.3^{\circ}$ & $1.0-2.2$ & $1.4^{\circ}$ & $0.9^{\circ}$ \\
STH & $1.9^{\circ}$ & $0.8-2.0$ & $1.5^{\circ}$ & $0.8-2.6$ \\
\hline
\end{tabular}

PR, prevalence ratio; CI, onfidence interval; STH, soil-transmitted helminths. ${ }^{\circ} \mathrm{P}<0.05$ according to Fisher exact test. 
of the study population had concomitant parasitic infections, most commonly A. lumbricoides and T. trichiura. These STHs appeared frequently in this municipality, probably due to the association of waterborne contamination with their life cycles. The high frequency of these co-infections suggests an important focus maintaining transmission of these parasites, which are usually spread by fecal-oral routes (Veronesi and Focaccia, 2009).

The human host can harbor many different species of parasites at the same time and the fact that the external environment presents a high degree of contamination increases the probability of infection with multiple parasitic infections. By analyzing the distribution patterns of infected subjects in the community, it can be determined whether the observed events display a systematic pattern rather than being randomly distributed. Our data support the understanding that associations between various parasitic diseases are linked to these agents' similar mechanisms of transmission, which make these infections good indicators of dysfunctional social and sanitary conditions (and vice versa). Apart from helminth infections, the relatively high prevalence of intestinal protozoa in our material points to a high degree of interpersonal contamination due to poor hygiene conditions (e.g. not washing hands, unhygienic keeping of fresh food, drinking untreated water and walking barefoot) or poor sanitation (quality of the sewage system). Mapping the spatial distribution of co-infection is indeed an important way to determine the areas of priority and implement cost-effective measures of control programs (Raso et al., 2006).

Da Silva et al. (2007) found that the prevalence and intensity of $S$. mansoni infection increased with increasing numbers of STH infections. They felt, however, that the strength of this association was not only because of socioeconomic or environmental conditions, but because of the interaction between the parasites as well and intrinsic host factors that increase susceptibility to several helminths (da Silva et al., 2007). We agree with that conclusion, but identified in this study that also the intermediate determinants for infectious diseases, such as housing and sanitation (water supply and sewage type), hygiene, purchasing power and education, are very important determinants. Infection with multiple intestinal parasites was found to be common in the community of Ilha das Flores, particularly in 11-to-20-year-old individuals, because their behavior makes them vulnerable to disease transmission.

Sociodemographic and behavioral variables were found to be significantly associated with $S$. mansoni and STH infections. The association of the minimum monthly income ( USD 300) with $S$. mansoni infection and intestinal parasites suggest that the influence of nutritional factors not evaluated in the present study may also be important disease determinants along with hygiene shortcomings related to housing conditions, such as the type of sewage used. We also found associations between drinking untreated water with $S$. mansoni, A. lumbricoides and T. trichiura infections. The former two parasites were associated with open-air sewages, while $S$. mansoni high-risk areas were found in households located near open-air sewages and septic tanks. As was observed and also recorded by IBGE (2007), the majority of the septic tanks in this area were not properly built suggesting that improved sanitation and measures leading to better personal economy are important steps when attempting to solve these health problems. Low educational level is also associated with $S$. mansoni infection. Education, when properly applied, leads people to acquire knowledge with respect to preventive measures that can help them to reduce the prevalence of parasitic diseases (Ferreira et al., 2000).

The exploratory analysis of spatial density kernel estimator made it possible to identify individuals from the areas of greatest vulnerability with regard to schistosomiasis infection in Ilha das Flores. The kernel estimator showed hotspots in places of the municipality where the population is poor, which was confirmed by the observation of a higher number of open-air sewage and septic tanks in the high-risk areas, together with the results of conventional statistical analysis which associated family income with infection. The proximity of the residential area of Ilha das Flores municipality with the rice field and the surface water, confirms the influence of these important determinants for $S$. mansoni infection.

Most specialized studies map snail infections or relate snail distributions to schistosomiasis prevalence with the objective of identifying high-risk areas, by studying human water contact sites (Barbosa et al., 2004, 2014; Kloos et al., 2004; Araujo et al., 2007). It is clear that the ability to predict the spatial distribution of infections improves our understanding of co-endemicity and its distribution, which can be used as evidence base for the spatial orientation of large integrated control programs (Brooker and Clements, 2009). Sophisticated analyses of spatial data are useful for the future planning of epidemiological control strategies in diseases depending on vectors, because they can identify the spatial combination of sanitation and social factors mapping the potentially risk areas. Khormi and Kumar (2011, 2012, 2014) used a geostatistical model with a combination of environmental and socioeconomic variables to model areas at risk of dengue fever in Saudi Arabia, by Getis-Ord Gi* statistics, while Bhunia et al. (2012) created distribution maps of visceral leishmaniasis in India to visualize the role of land use for disease transmission analyzed by a probabilistic approach. The georeferenced database created in our study can be used for future geostatistical analysis, using a combination of the data to map areas at risk for schistosomiasis.

Previous malacological studies by our group in this area have showed that the irrigation system impacts on the competitive selection replacing the native Biomphalaria straminea by $B$. glabrata (Barboza et $a l ., 2012$ ) which is more sensitive to dehydration and therefore favored by the irrigation system (Michelson and Dubois, 1979; Barbosa et al., 1993). B. glabrata is more easily infected by $S$. mansoni and this is probable one of factors influencing schistosomiasis transmission in this area (Barboza et al., 2012). In the present study, we mapped land use and showed the proximity of rice fields to the residential areas as an additional risk besides the presence of open-air sewages and septic tanks in the areas with higher infection density. Our results suggest that the main contamination in Ilha das Flores occurs in the proximity of the houses of the inhabitants. In fact, during the raining season, the surface water overflows inside the houses in this municipality. These data suggest that it is important to improve the sanitation level of this municipality as a strategic move for control for $S$. mansoni transmission.

\section{Conclusions}

Poverty is strongly associated with $S$. mansoni as well as intestinal helminths and protozoal infection based on a combination of conventional statistical and geospatial analysis that identifies potential areas of transmission, where a set of social and behavioral features maintain these endemic diseases. The conditions of vulnerability to endemic diseases using kernel modelling, pointing to a set of possibilities for the occurrence of diseases, can contribute to building a system of monitoring, epidemiological surveillance, and hygiene-oriented measures to guide the actions of national schistosomiasis control programs. The georeferenced database created in this study will help future development of a geostatistical model that can include also water contact, vector distribution, houses with open-air sewage and septic tanks, i.e. 
information relevant to regional planning efforts to effectively control these diseases.

\section{References}

Araujo KC, Resendes AP, Souza-Santos R, Silveira Junior JC, Barbosa CS, 2007. Spatial analysis of Biomphalaria glabrata foci and human cases of mansoni schistosomiasis in Porto de Galinhas, Pernambuco State, Brazil, in the year 2000. Cad Saude Publica 23:409-17.

Barbosa CS, Araujo KC, Antunes L, Favre T, Pieri OS, 2004. Spatial distribution of schistosomiasis foci on Itamaraca Island, Pernambuco, Brazil. Mem Inst Oswaldo Cruz 99:79-83.

Barbosa CS, Barbosa FS, Arruda F, 1993. Long-term controlled field experiment in the competition between of Biomphalaria (Mollusca Basommatophora), the snail vectors of Schistosoma mansoni in Northeastern Brazil. Cad Saude Publica 9:170-6.

Barbosa CS, Barbosa VS, Nascimento WC, Pieri OS, Machado Araújo KCG, 2014. Study of the snail intermediate hosts for Schistosoma mansoni on Itamaracá Island in northeast Brazil: spatial displacement of Biomphalaria glabrata by Biomphalaria straminea. Geospat Health 2014;8:345-51.

Barboza DM, Zhang C, Santos NC, Silva MMBL, Rollemberg CVV, Amorim FJR, Ueta MT, Melo CM, Almeida JAP, Jeraldo VLS, Jesus AR, 2012. Biomphalaria species distribution and its effect on human Schistosoma mansoni infection in an irrigated area used for rice cultivation in northeast Brazil. Geospat Health 6:103-9.

Bethony J, Williams JT, Kloos H, Blangero J, Alves-Fraga L, Buck G, Michalek A, Williams-Blangero S, Loverde PT, Correa-Oliveira R, Gazzinelli A, 2001. Exposure to Schistosoma mansoni infection in a rural area in Brazil. II: Household risk factors. Trop Med Int Health 6:136-45

Bhunia GS, Kesari S, Chatterjee N, Kumar VP, 2012. Localization of kala-azar in the endemic region of Bihar, India based on land use/land cover assessment at different scales. Geospat Health 6:7793.

Brooker S, Clements ACA, 2009. Spatial heterogeneity of parasite coinfection: determinants and geostatistical prediction at regional scales. Int J Parasitol 39:591-7.

Brooker S, Beasley M, Ndinarotan M, Madjiouroum EM, Baboguel M, Djenguinabe E, Hay SI, Bundy DAP, 2002. Use of remote sensing and a geographical information system in a national helminth control programme in Chad. B World Health Organ 80:783-9.

Bundy DA, Chandiwana SK, Homeida MM, Yoon S, Mott KE, 1991. The epidemiological implications of a multiple-infection approach to the control of human helminth infections. T Roy Soc Trop Med H 85:274-6.

Campos MR, Valencia LI, Fortes BP, Braga RC, Medronho RA, 2002. Spatial distribution of Ascaris lumbricoides infection. Rev Saude Publ 36:69-74.

Chitsulo L, Engels D, Montresor A, Savioli L, 2000. The global status of schistosomiasis and its control. Acta Trop 77:41-51.

Clements AC, Deville MA, Ndayishimiye 0, Brooker S, Fenwick A, 2010. Spatial co-distribution of neglected tropical diseases in the east African great lakes region: revisiting the justification for integrated control. Trop Med Int Health 15:198-207.

Da Silva JC, Lima FDT, Vidal CH, Azevedo HCR, 2007. Schistosomiasis mansoni presenting as a cerebellar tumor. Case report. Arq Neuro-
Psiquiat 65:845-7.

Da Silva NR, Brooker S, Hotez PJ, Montresor A, Engels D, Savioli L, 2003. Soil-transmitted helminth infections: updating the global picture. Trends Parasitol 19:547-51.

Ferreira MU, Ferreira CS, Monteiro CA, 2000. Tendência secular das parasitoses intestinais na infância na cidade de São Paulo (19841996). Rev Saude Publ 34:73-82.

Gazzinelli A, Bethony J, Fraga LA, LoVerde PT, Correa-Oliveira R, Kloos $\mathrm{H}, 2001$. Exposure to Schistosoma mansoni infection in a rural area of Brazil. I: Water contact. Trop Med Int Health 6:126-35.

Gomes FJ, Hoshino-Shimizu S, Dias LCS, Araujo AJSA, Castilho VLP, Neves FAMA, 2004. Evaluation of a novel kit (tf-test) for the diagnosis of intestinal parasitic infections. J Clin Lab Anal 18:132-8.

Hotez PJ, Bethony JM, Diemert DJ, Pearson M, Loukas A, 2010. Developing vaccines to combat hookworm infection and intestinal schistosomiasis. Nat Rev Microbiol 8:814-26.

IBGE, 2007. Censo demográfico 2007. Características gerais da população. Resultados da amostra. Available from: http://www.ibge.gov.br/home/estatistica/populacao/contagem2007/

Khormi HM, Kumar L, 2011. Examples of using spatial information technologies for mapping and modelling mosquito- borne diseases based on environmental, climatic, socio-economic factors and different spatial statistics, temporal risk indices and spatial analysis: a review. J Food Agric Environ 9:41-9.

Khormi HM, Kumar L, 2012. Assessing the risk for dengue fever based on socioeconomic and environmental variables in a geographical information system environment. Geospat Health 6:171-6.

Khormi HM, Kumar L, 2014. Climate change and the potential global distribution of Aedes aegypti: spatial modelling using GIS and CLIMEX. Geospat Health 8:405-15.

Kloos H, Passos LK, Loverde P, Oliveira RC, Gazzinelli A, 2004. Distribution and Schistosoma mansoni infection of Biomphalaria glabrata in different habitats in a rural area in the Jequitinhonha Valley, Minas Gerais, Brazil: environmental and epidemiological aspects. Mem Inst Oswaldo Cruz 99:673-81.

Michelson EH, Dubois L, 1979. Competitive interactions between two snails hosts of $S$. mansoni. Laboratory studies on $B$. glabrata and $B$. straminea. Rev Inst Med Trop Sao Paulo 21:246-53.

Rasbash J, Steele F, Browne WJ, Goldstein H, 2012. User manual MLwiN version 2.26. Centre for multilevel modelling. University of Bristol ed., UK.

Raso G, Vounatsou P, McManus DP, Utzinger J, 2007. Bayesian risk maps for Schistosoma mansoni and hookworm mono-infections in a setting where both parasites co-exist. Geospat Health 2:85-96.

Raso G, Vounatsou P, Singer BH, N'Goran EK, Tanner M, Utzinger J, 2006. An integrated approach for risk profiling and spatial prediction of Schistosoma mansoni-hookworm coinfection. P Natl Acad Sci USA 103:6934-9.

Rollemberg CV, Santos CM, Silva MM, Souza AM, Silva AM, Almeida JA, Almeida RP, Jesus AR, 2011. Epidemiological characteristics and geographical distribution of schistosomiasis and geohelminths, in the State of Sergipe, according to data from the Schistosomiasis Control Program in Sergipe. Rev Soc Bras Med Trop 44:91-6.

Veronesi R, Focaccia R, 2009. Tratado de infectologia. Atheneu ed., Sao Paulo, Brazil.

WHO, 2010. Initiative for vaccine research (IVR). World Health Organization, Geneva, Switzerland.

WHO, 2014. Schistosomiasis: number of people receiving preventive chemotherapy in 2012. World Health Organization, Geneva, Switzerland. Available from: http://www.who.int/wer/ 2014/wer8902/en/ 8902/fr/ 